\title{
Indian Banks: Practices and HRD
}

\author{
Dr Jai Prakash Tripathi ${ }^{1}$, Ms. Harshita Bhatnagar ${ }^{2}$ \\ ${ }^{1}$ Dean, MBA, Sri Satya Sai University of Technology \& Medical Sciences, Sehore \\ ${ }^{2}$ Sri Satya Sai University of Technology \& Medical Sciences, Sehore
}

\begin{abstract}
Successful administration of HR assumes a key part in sound administration of banks as human asset administration is a focal sub arrangement of present day administration framework. This cliché is all around perceived by even market economies of USA, UK, and France and so on. Administration of human re-sources adjustment to any sort of progress and viable working of banks is conceivable just when HR are produced. Consequently, HRD encouraged for all round advancement of banks notwithstanding permitting them to be dynamic and receptive to the ecological changes. The review on Human Resource Development in Banks, under present financial situation in the nation is fundamental to comprehend bank's available HRD reasoning, practice and result with a view to offer proposals for detailing of right theory and routine of HRD in Banks. The present review has been embraced in perspective of the nonappearance of efficient examined regarding the matter. Nationalization has changed the mind boggling particle and measurements of Commercial Banking in India. It hurried the pace of geological and practical enhancement. The new measurements have set the changing obligations on the shoulders of business banks, for example, development of branch workplaces to unbanked and remote country zones on a huge scale in order to cover little scale area, cabin and rustic ventures, independently employed people, artisans, weaker segments of the general public, little dealers and different people of little means. The review covers all the essential zones of human asset advancement in banks. These territories incorporate applied elucidation about human asset and human asset advancement in banks, basics of HRD, and the sub-arrangement of human asset improvement like execution evaluation, preparing, administration improvement, profession arranging and advancement, association advancement, participative administration, quality circles and so on. These essential zones of HR advancement will be considered completely to the most extreme degree through the method for discourse, interviews, reports, accounts, perceptions and so on.
\end{abstract}

Keywords: dimension, conceptual, career planning.

\section{Introduction}

Twenty -first century HR is rising to extraordinarily consolidate exercises and procedures of human asset administration (HRM), human asset improvement (HRD), and hierarchical advancement (OD), three fields that "grew up" unmistakable from each other .Contributing deliberately to associations requests that HRM, HRD and OD arrange, accomplice and contemplate how they relate and how they do impacts individuals and associations .The essential anxiety of the bank ought to be to acquire appropriate mix of human asset administration methodologies with the business techniques. It ought to quicker durable collaboration and make duty to enhance the proficiency of its human capital. More than operational abilities today are saving money require these „soft aptitudes' to go to the necessities and prerequisite of the clients at the counter.

Banks need to comprehend that the capital and innovation thought to be the most vital mainstays of saving money are replicable, yet not human capital, which should be seen as a profitable re-hotspot for the accomplishment of upper hand. The long haul vision for India's managing an account framework is to change itself from being a local one to the worldwide level may sound unrealistic at present.

To take up this industry to the statures of universal brilliance requires blend of new innovations, better procedures of credit and hazard evaluation, treasury administration, item enhancement, inside control, outer directions and HR and no more. The primary difficulties confronted by Banks in our nation are the pretended by money related instrumentation in various periods of business cycle, the rising impulses of the new prudential standards and seat denoting the Indian budgetary framework against global models and best practices. There is a requirement for presentation of new innovation, expertise building and scholarly capital development. The most critical need in this administration industry is actually the HRD. Amid the early period of managing account advancement in India after freedom, open doors for work of the informed labor were generally constrained. This sec-tor was the favored boss for the informed people in the nation notwithstanding affable administrations. As of late, this position has changed drastically. Certain rigidities have additionally created in HRD inside the keeping money framework as this framework is open part. Its progressive structure offers inclination to status over execution, and it is not the best condition for pulling in the best ability from among the youthful. How well Challenges are met will basically rely on upon the degree to which the bank's use their essential resources i.e., 
HR with regards to the changing financial and business condition. It is normal that the Indian keeping money and fund framework will be comprehensively aggressive. For this the market players should be fiscally solid and operationally effective. Capital would be a key calculate building a fruitful foundation. The managing an account and back framework will enhance aggressiveness through a procedure of solidification, either through mergers and acquisitions through key organizations together. Indian Banking framework has assumed a pivotal part in the financial advancement of the nation. The framework is required to keep on being touchy to the development and advancement needs of the considerable number of portions of the general public. Other than honing HR in various units it is additionally a mammoth errand for the banks to confront the focal and external difficulties. In various way the HR office deals, back and make the vital after some time to accomplish its definitive goals. Checking and additionally changing the procedure likewise allows the business to adapt up to the present request.

\subsection{Prior Studies}

Human asset improvement is a procedure through which workers in an association are helped to understand their maximum capacity for their present and future occupations. It includes long haul point of view which envisions change through contribution and responsibility for change by the members. HRD trusts that person in an association have boundless potential for development and advancement and that their potential can be worked through suitable and methodical endeavors.

The contraction HRD signifying, "HR advancement" is production of western nations; they regard and arrangement human compel as asset. Assets are investigated, abused and disposed of after their utilization. Ceaseless utilization of assets make them feeble and vain, they rot with time. In any case, individuals get to be distinctly more astute, more grounded and develop from inside each test issue en-countered. Astuteness and quality in individuals acknowledged with time however utilization of asset dependably make them powerless, pointless and deteriorate. D.V. Ramana Murthy has talked about in this article on "Human Factor in Banks," the noteworthiness of human figure and exchange unions the banks. S.R. Varde in his paper on "Labor Planning" at the level of an Indian business bank managed the viewpoints like fundamental structure of labor arranging, linkage of labor plan to different arrangements, interrelationship of different labor capacities, destinations of labor arranging in Indian business banks, life systems of labor arrangements and strategies of labor arranging. N.R. Seth talked about development, working and advance of exchange unions in Indian banks. P. Subba Rao, have talked about the part of guiding, execution directing and activity arranging in his paper on "Bank Branch Manager as a Counselor." T.V. Rao, in his book on "The HRD Machinery" clarified HRD instruments, procedures and results, HRD Departments and their undertakings, organizing the HRD capacity, qualities, and fitness prerequisite of HRD directors, creating HRD chiefs, traps and allurements of HRD troughs and HRD instruments". Balader R. Sharma in his review on "Human Resource Management in Banking Industry" concentrated administrative convictions, work innovation and authoritative atmosphere. P. Amsa in his paper "Organization culture base for compelling HRM in Banks" considered HRD related ranges to sum things up notwithstanding different issues identified with human asset administration. T.P. Raman in his paper on "HRD in State Bank of India" clarified the act of HRD and different procedures of HRD in State Bank of India. His paper is for the most part in view of his work involvement in the bank instead of a review. R. K. Agarwal. In his paper on "HRD" in State Bank of Patiala" clarified the goal and structure of HRD office, HRD atmosphere and different methods of HRD in the Bank. This paper likewise experiences similar restrictions of the T.P. Raman"s paper.

The current accentuation on human asset administration, e.g. Story (1992), Torrington and Tan Chee Haut (1994), proposes that not exclusively is the administration of work being given more consideration, however that the issues examined are more extensive and more vital and also strategic (see additionally Wilkinson and Marchington, 1994). Mill operator (getting from Porter (1995) characterizes key human asset administration as those choices and activities which concern the administration of workers at all levels in the business and which are identified with the usage of techniques coordinated towards making and maintaining upper hand. (1987, p.352) . In this manner, not at all like the customary fringe capacity of numerous faculty chiefs, the more current style of human asset troughs endeavors to:,, relate work force practices to convictions, to interface every last procedure of the enlistment, acceptance, preparing, examination remunerating of people to a general arrangement of enunciated convictions of organizationee (Hunt, 1984, p.16) Krishna and Rao (1997) completed a thorough observational review Organizational and HRD Climate in BHEL: An Empirical Study, and found that HRD atmosphere in the association supported center and senior supervisors to explore different avenues regarding new strategies and experiment with inventive thoughts. Sharma and Pooja Purang (2000) in their review Value Institutionalization and HRD Climate: A Case Study of a Navratna open part association, found a positive relationship between esteem regulation and HRD atmosphere in a vast open segment association, which means consequently that a superior and more moral condition of the association should prompt to a superior HRD atmosphere for the association. 


\section{Destinations of the Study}

1) To enquire into the HRD theory of banks.

2) To concentrate the hierarchical and HRD atmosphere in the banks.

3) To enquire into the acts of different HRD methods, and

4) To concentrate the results of human asset advancement for the banks, singular workers, bunches and the general public every where in both private and in addition open segment banks.

In the satisfaction of these goals, a nearby review is made on extremely vital ranges of human asset improvement in banks. The position before nationalization is additionally considered with a view to assess the progressions better.

\section{Research Methodology}

It was exceptionally hard to acknowledge and comprehend the HR improvement unless re-course is made to the meeting technique. Meetings and exchanges composed with the chose agents of administration of different Commercial Banks, Staff Training Colleges, Indian Institute of Banker, Bombay; National Institute of Bank Management, Pune; Indian Bank Association, Bombay; Banking Service Recruitment Boards, Trade Unions and with workers of different business banks. A different survey arranged for this reason to draw upon their rich individual assessments, encounters and so on., which can't discover a place in the reports and records. Interviews directed with the students who experienced preparing and administration advancement program, their prevalent, subordinates and associates so as to learn the effect of these projects on employment execution and conduct. Another strategy received for this review is the gathering of auxiliary information from different open part banks and private segment banks. Different proper factual strategies utilized for investigating the information. The measurable examination and information supplemented by the data gathered through meetings and individual perception to determine viable and important conclusions. The information and data gathered from different sources. Genuine information gathered from the yearly reports of the banks; staff preparing schools, house magazines and different records of the banks, reports and different records of the exchange unions. The review warrantees various excursions to the head office, local workplaces, branch workplaces and staff preparing universities of respondent Public Sector Banks and Private Sector Banks and National Institute of Bank Management, Pune; Indian Institute of Bankers, Bombay; and Indian Banks ${ }^{e e}$ Association, Bombay. Amid these visits, libraries of all banks and different saving money foundations used to experience various pertinent reports and books. So as to study the substance of HR practice in today's situation in Indian Banks we have to know the difficulties which our managing an account industry is confronting.

\section{Challenges Faced By Banking Industry}

Here are the ten difficulties that the HR work in India faces:

1) The above all else challenge that HR work in India countenances is to change over the bounteous populace pool into helpful human asset.

2) Training and improvement of human asset to coordinate constantly changing industry requests re-quires HR to grow new and imaginative thoughts that suit individual and in addition industry criteria.

3) Employee inspiration and fulfillment is another territory of sympathy toward the HR today. With a specific end goal to lessen weakening, HR needs to understand that money related requirements are by all account not the only drive for an individual and that a feeling of belongingness must be guzzled in workers.

4) With the expansion in number of employment choices accessible these days, the HR capacity of an association must take mind that they contract those individuals who have confidence in long haul duty to the association. The HR then should respond to the call of holding them by creating maintenance procedures like Holiday arrangements fun-at-work and so on.

5) Because of vicious rivalry, HR in India likewise confronts the undertaking of building focused advertisement vantage for the organization over national and universal contenders.

6) The developing significance that organizations are these days providing for cost-cutting has postured HR with the test to limit consumption on HR not trading off on the efficiency.

7) Since right-estimating has been a developing pattern in Indian association, the HR now confronts the undertaking of distinguishing and holding the key representatives of an association and giving up those that sometimes fall short for its future necessities.

8) HR additionally confronts the test of making an adjusted association that begins from mergers and acquisitions. HR needs to acclimatize those arrangements that are commonly pleasing to the organizations being converges and in addition beneficial for the new association.

9) Globalization postures HR with difficulties, for example, exile and repatriation. HR needs to prepare workers that leave their country for satisfying a remote task. It likewise needs to master vide such workers with sufficient good support and guarantee them of professional stability on their re-turn. 
10) With multinational associations on the ascent, HR needs to concentrate on issues, for example, culturally diverse preparing so that issues that can emerge as a result of contrasts in global expert qualities can be reduced.

\section{Meeting HR Challenges}

The managing an account segment has been developing at a quick pace in India in the terms of its size as well as regarding the administrations being given. With banks achieving the remote territories in the nation one can envision positive things like budgetary guide to agriculturists and expanded monetary mindfulness. Notwithstanding, with the expansion in size and exercises of banks, the quantity of banks in private parts has likewise expanded along these lines posturing challenges like cost-productivity, innovative progression, and believability related issues. The errand before the HR is to create procedures that help banks in increasing upper hand and energize advancement in its items and administrations.

\subsection{Overseeing Human Resource}

Considering the above HR challenges which our Indian keeping money industry is confronting, we can deal with the HR by legitimate Planning like

- Hiring the correct individual for the correct employment

- Retaining and Developing

- Managing individuals/directing post employment surveys

\subsection{Procuring the Right Person for the Right Job}

In evaluating whether the "perfect individual" has been chosen for the "right occupation", the most noticeable hypothetical idea that rises is the idea of "fit". Diverse journalists underscore distinctive sorts of fit. Sekiguchi (2004: 179) in a survey of writing on individual condition fit talks about two sorts of fit that develop as the most noticeable sorts of fit: individual employment fit and individual association fit. In seeking after individual occupation fit, organizations look to coordinate the employment holder's learning, aptitudes and capacities to the necessities of the employment. Organizations can find out individual association fit by concentrating on how well the individual fits with the way of life or estimations of the organization and the individual's ability to function admirably with other organization workers.

\section{Banks need to get ready for the accompanying:}

- An enduring, painstakingly adjusted enlistment program,

- As quick mechanical changes change business - consistent expertise up-degree.

- Another era of the workforce working nearby a more established era as a group.

Keeping money, it is a co-operation and these new circumstances require social conformities and in this manner, change administration.

\subsection{Holding and Developing Employees}

We might have the capacity to get the most suited individuals for our work yet then the test is to hold these individuals and to create them. There are a few measurements to this issue, for example, preparing/reskilling of workers, execution estimation, advancement approach, exchange strategy, ability administration, correspondence, and so on. In this review some of them for examination.

\subsection{Preparing and Development}

With extraordinary development of banks it calls for productive and very much prepared staff individuals to deal with/manage the purchaser needs. Banks are taking care of business as monetary center point for their customers to develop in size and all around perceived on the planet advertise. To force customers banks are putting forth conventional with propel administrations like SMS keeping money, ATM, web managing an account, need saving money, demat. So we can state that it takes into account the need of the base to the most astounding class of society giving something to everybody. General banks have turned out to be current's grocery store expanding practically every office of keeping money under one rooftop.

Banks like Bank of Baroda are directing Grooming and behaviors programs for forefront workers and furthermore for representatives chose for abroad presenting all together on enhance their administration levels and subjective collaboration with clients and different partners better. SEED (Self proficiency and viability advancement) program being keep running for bleeding edge staff of the Bank so as to enhance their administration aptitudes and overhauling productivity.

In Punjab National Bank, in the light of the vast scale HR crevices that Bank is probably going to confront in the following couple of years requirement for Succession Policy has been felt. The Policy visualizes mapping of the 'current pool' against the 'future necessity' from the anticipated business figure to guarantee that 
sufficient number of authorities are accessible in the pool and furthermore to predict the surplus/shortage in the pool for determining the prerequisite of progression in a specific vertical. Bank has a three level prepare ing set up containing Central Staff College (CSC) at Delhi at peak level taking into account preparing necessities of Top/Senior/Middle Management Grade officers, three Regional Staff Colleges (RSCs) situated at Belapur Navi Mumbai, Lucknow and Panchkula for preparing needs of Senior/Middle/Junior Management officers and additionally worker staff and seven Zonal Training Centers (ZTCs) at Dehradun, New Delhi, Jaipur, Kolkata, Kozhikode, Ludhiana and Patna taking care of the preparation needs of Middle/Junior Management Grade officers and Workman Staff. IT Training Center situated at Faridabad takes into account the preparation needs of officers only in the zones of Information Technology.

\subsection{Execution Management}

Managing an account administration is one part where an incredible level of consideration is being paid to execution evaluation framework. A few of the nationalized banks have changed their execution evaluation framework or are evolving them. In the vast majority of the banks that takes after the conventional framework, their officers are being evaluated on the accompanying qualities:

- General Intelligence

- Job Knowledge

- Initiative and genius

- Supervision

- Business Capacity

- Ability to survey sound

- Business recommendations

- Dependability

- Relationship with junior and senior associates

- Relationship with open

- Conduct, behavior, Managerial capacity

- Failures that pulled in issue of caution by bosses

A few of the banks likewise have self evaluation as a piece of execution examination, albeit for the most part such self evaluation is even more a correspondence of accomplishments. A reasonable, straightforward and target instrument for execution administration is an unquestionable requirement for all banks in light of the fact that a compelling Performance Management System is the way to ability administration and progression arranging. RBI is in no time going to present another Performance Management System that will take a shot at objective setting, potential examination of entertainers and building up an ability pipeline. With every one of these progressions we are likewise going to face significant difficulties on the Talent Management front. In coming circumstances, the work compel will get mind boggling and there will be a need to juggle a wide assortment of individuals with fluctuated needs and inclinations, bringing about a variety of connections between the association and the individuals who work for it. Dwindle Drucker had, over 10 years back, communicated the requirement for what he called "non-customary" work relations: adaptable timetables, contract game plans, virtual groups, and so on.

\section{Some other HR practices and advantages given to representatives:}

HDFC Bank accommodates tip to all representatives. The advantage is as singular amount installments to vested representatives on abdication, retirement, and demise while in business or on end of work of a sum proportionate to 15 days fundamental pay payable for each finished year of administration. Vesting endless supply of five years of administration.

\section{Superannuation}

Workers of the Bank, over a recommended review, are qualified for get retirement benefits under the Bank's Superannuation Fund. The Bank contributes an entirety comparable to $13 \%$ of the representative's qualified yearly essential pay (15\% for the Managing Director, Executive Directors and for certain qualified past Centurion Bank of Punjab (,eCBoP $\left.{ }^{e e}\right)$ staff) to insurance agencies, which oversee the reserve. The Bank has no obligation for future superannuation support benefits other than its commitment, and perceives such commitments as a cost in the year acquired, accordingly commitment is in the way of characterized commitment.

Here and now Employee Benefits In State Bank of India the undiscounted measure of here and now representative advantages, for example, health advantages, easygoing leave and so forth which are relied upon to be paid in return for the administrations rendered by workers are perceived amid the period when the worker renders the administration. 
The Bank works a Provident Fund plot. Every single qualified representative are qualified for get benefits under the Bank ${ }^{\text {ee }}$ s Provident Fund plot. The Bank contributes month to month at decided rate (presently $10 \%$ of representative's fundamental pay in addition to qualified stipend). These commitments are transmitted to a trust built up for this reason and are charged to Profit and Loss Account. The Bank accommodates annuity to every qualified representative. The advantage is as regularly scheduled installments according to tenets and standard installments to vested representatives on retirement, on death while in business, or on end of work. Vesting happens at various stages according to rules.

\section{Recommendations}

The saving money area has developed from a couple of organizations basically required in store acknowledgment and exchange fund into a complex multi player markets where vast number of business banks, budgetary foundations and specific banks are working with different item exercises. In the same way as other sorted out segments, managing an account requires multi layer labor for its different necessities of experts and care staff. The range may require sensibly taught security watches from one viewpoint and a profoundly instructed and prepared proficient as head of corporate back. With advancement of exercises inside the keeping money segment, for instance, more accentuation on customer and house fund and individual credits, and so on. Managing an account has transformed itself into a more market based business where banks have extended their achieve more to client's entryway venture bigly making saving money more reasonable. This has additionally highlighted the requirement for legitimate advancement of labor to run banks productively. Shrewd banks have understood this need and have found a way to keep their workforce propelled through legitimate consolation like man of the month grant, rehash get-together, meetings, sports occasions, meals, organization supported travel, reunions, and so forth.

Disregarding every one of these helps there still exist a few lacunas in the HRM hones in managing an account industry. A portion of the particular recommendations in light of review of writing and in addition the gathering discourses and study are given here under:

1) There ought to be an adjusted tradeoff between authoritative need and individual need. Add up to obtuseness to individual inclination offers ascend to disappointment sooner or later of time, which as an outcome has a genuine harming impact on the authoritative development itself.

2) While there must be prizes for execution, non-execution must be rebuffed/reproved. Advancements must be just on legitimacy.

3) There must be uniform, unbiased and adjusted "worker execution survey framework. "This framework in certainty needs an aggregate survey.

4) Enthusiastic and lovely conduct of staff to the client is fundamental.

5) There must be a plainly characterized arrangement of progression arranging and vocation development arranging in banks.

6) Attitudinal changes are required at the top level.

7) Human asset Balance Sheet ought to go with budgetary proclamations.

8) Keeping in mind the end goal to wind up HRD cognizant, the Public Sector Banks ought to permit autonomous working of HRD segment, where the top individual ought to act naturally a decent fruitful broker, a genuine HRD individual free from any inclinations.

9) More openness, straightforwardness in individual matters, high estimation of human pride, individuals arranged administration framework, making belongingness and trust, two-way correspondence.

10) Banks ought to have a framework, whereby the preparation needs of a worker are distinguished and are properly satisfied at each phase of profession development.

11) Have exceptional $R$ and $D$ wings in HRD Department for continuous in house and outer research improvement, survey and execution of HRD arrangements.

12) There ought to be honor plans managed by prestigious associations and Govt. organizations for best HRD arrangements and Practices among Public Sector Banks, and so forth.

\section{Conclusion}

To finish up, Organizations all over are hurrying to actualize the most recent thoughts on administration, now and again to the point of abuse. The real test now for banks and some other association is consequently how to build up their social engineering that creates scholarly capital as the quintessential driver of progress. Building up the individual or human limit is an essential component of building limit and, truth be told, limit building activities are currently progressively turning out to be very nearly a record of institutional quality. Taking the saving money industry to the statures of brilliance, particularly notwithstanding the a temple point by point rising substances, will require a mix of new innovations, better procedures of credit and hazard evaluation, treasury administration, item enhancement, inside control and outside directions and, not the minimum, HR. 


\section{References}

[1]. Leon C Megginson, Personnel and Human Resources Administration, Richard D. Irwin Inc. Homewood,Illionis, 1977,p.4

[2]. Arthur Lewis, the History of Economic Growth, Geoge Allen and Unwin Ltd., London, 1965, p.

[3]. Leon C. Megginson, Personnel, Richard d. Irwin Inc., Homewood, Illionis, 1972, p.14.

[4]. Eli Ginzberg, "Man his work" , Edited by Dale S. Beach, Managing People at work, Macmillan Publishing co, Inc., New York,1980,pp. 3-4

[5]. Sar, A Levitan, Garth L. Mangum and Ray Marshall, Human Resources and Labour Markets, Harper and Row publishers, New York, pp, 1-2

[6]. M. N. Rudrabasavaraj, Dynamic personnel Administration, Himalaya Publishing House, Bombay, 1979 , p.39

[7]. Douglas Mc Gregor, The Human Side of Enterprise, Tata McGraw Hill Publishing Co., Ltd. Bombay, 1971, pp.3-4

[8]. Dunlop. Lohn T. Et.Al, Industrialism and industrial Man Reconsidered, Some Perspective on a Study over Two Decades of Problems of labour and Management in Economic Growth, The Inter-University study of Human resources in National Development, New Jersey, 1975,p.41.

[9]. Ernest Dale, Management Theory and Practice, McGraw Hill Book Company, New York, 1965.

[10]. Edwin. B. Flippo, Principles of Personnel Management, McGraw Hill Kogakusha Ltd., Tokyo, 1969, p.8

[11]. Human Resource Management in. Banks - Need for a New Perspective*. K. C. Chakrabarty. Shri Alok Misra, CMD, Bank of India, Dr. K. Ramakrishnan 